\title{
Erratum to: Environmental cooperation: ratifying second-best agreements
}

\author{
Pierre Courtois • Guillaume Haeringer
}

Published online: 7 February 2012

(C) Springer Science+Business Media, LLC 2012

\section{Erratum to: Public Choice (2012) 151:565-584 \\ DOI 10.1007/s11127-010-9759-6}

Due to an unfortunate turn of events the acknowledgement was omitted from the article. Please find the below acknowledgement that should be regarded by the reader as part of the article.

Acknowledgements Guillaume Haeringer gratefully acknowledges support from the Spanish Ministry of Science and Innovation through grant "Consolidated Group-C" ECO2008-04756 and FEDER, from the Generalitat de Catalunya, Departament d'Universitats, Recerca i Societat de la Informació through the grant SGR2009-0419.

The online version of the original article can be found under doi:10.1007/s11127-010-9759-6.

P. Courtois $(\bowtie)$

Dept. of Economics, INRA, Montpellier, France

e-mail: courtois@supagro.inra.fr

G. Haeringer

Dept. of Economics, Universitat Autonoma de Barcelona, Bellaterra, Spain 